\title{
Spectroelectrochemical study of the oxidation of aminophenols on platinum electrode in acid medium
}

\author{
Horacio J. Salavagione a, Joaquín Arias b, Pedro Garcés c, Emilia Morallcúrron ${ }^{\text {b,*, }}$, \\ Cesar Barbero ${ }^{\mathrm{a}}$, José Luís Vázquez ${ }^{\mathrm{b}}$ \\ a Departamento de Química, Universidad Nacional de Río Cuarto, Agencia Postal No. 3, 5800 Río Cuarto, Argentina \\ ${ }^{\mathrm{b}}$ Departamento de Química Física, Universidad de Alicante, Apartado 99, 03080 Alicante, Spain

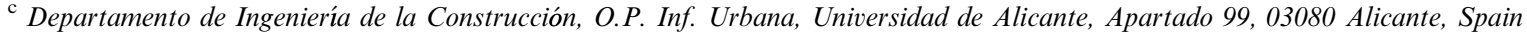

Received 30 June 2003; received in revised form 24 October 2003; accepted 5 November 2003

\begin{abstract}
The electrochemical oxidation of para-, meta- and ortho-aminophenols was carried out using a platinum electrode in aqueous acid medium. The spectroscopic results indicate that $p$-aminophenol suffers hydrolysis giving the formation of hydroquinone/ $p$ benzoquinone. $\mathrm{CO}_{2}$ has been detected by in situ FTIR spectroscopy as the main soluble oxidation product. The $m$-aminophenol oxidation produces a blocking polymeric film on the platinum surface. The main oxidation products detected by in situ infrared spectroscopy were $\mathrm{CO}_{2}$ and quinone. Cyclic voltammetry and in situ FTIR spectroscopy were combined to study the redox processes of the conducting polymer obtained in the $o$-aminophenol oxidation. The spectroscopic results indicate that phenoxazine units are produced during the oxidation/reduction of poly $(o$-aminophenol).
\end{abstract}

(c) 2003 Elsevier B.V. All rights reserved.

Keywords: Aminophenol; FTIR spectroscopy; Electroactive polymers; Cyclic voltammetry

\section{Introduction}

Aminophenols are interesting electrochemical materials since, unlike aniline [1] and other substituted anilines [2], they have two groups $\left(-\mathrm{NH}_{2}\right.$ and $\left.\mathrm{OH}\right)$, which could be oxidized. Therefore, they could show electrochemical behavior resembling anilines [1-3] and/or phenols $[4,5]$. An important factor would be the relative position of the amino and hydroxyl group in the aromatic ring. Accordingly, the reported electrochemical properties of the three positional isomers (ortho, meta and para) are strongly different. $p$-Aminophenol (pAP) is a well-known compound which, in its simple form, or derivative [6], has been used as redox agent in photography. In neutral media, it is oxidized to complex oligomeric dyes that could be used in enzymatic assays [7]. Taj et al. [8] have studied the electropolymerization of $p$ -

\footnotetext{
${ }^{*}$ Corresponding author. Tel.: +34-9-6590-9590; fax: +34-9-65903537.

E-mail address: morallon@ua.es (E. Morallón).
}

aminophenol on a platinum electrode, which yields a soluble electroactive polymer in organic solvents.

Konopelnik et al. [9] have studied the oxidation of $m$ aminophenol (mAP) in aqueous solution on $\mathrm{SnO}_{2}$ electrodes. According with these authors, only the amino group of $m$-aminophenol undergoes oxidation while the hydroxyl group remains unchanged.

On the other hand, the oxidation of $o$-aminophenol (oAP) on different electrode materials (platinum, carbon, gold, etc.) in aqueous acid medium was shown to form an electroactive polymer [10-12]. The polymer has been characterized [12-15], its electrochemical and electrochromic properties studied [11,16-22] and the material applied to sensors [23-26] and metal deposition [27]. Early on, the oxidation mechanism of oAP was studied using electrochemical techniques [28]. The formation of a soluble dimer (3-aminophenoxazone) was proposed and the chemical synthesis of the dimer allows this assignation to be proved [29]. The formation of this compound as a soluble product in acid medium has been revised by Goncalves et al. [30] using platinum and 
glassy carbon electrodes. The soluble product has been characterized as 2-aminophenoxazin-3-one (APZ), a product also prepared by chemical oxidation of oAP. The oxidation of $o$-aminophenol in basic media resembles that of phenol with formation of an electroinactive film [12].

In the present work, cyclic voltammetry and in situ FTIR spectroscopy have been combined to study the oxidation mechanism of aminophenols and the behavior of its polymeric products on a platinum electrode in acid medium.

\section{Experimental}

The test solutions were $1 \mathrm{M} \mathrm{HClO}_{4}$ prepared from Merck Suprapur concentrated acids. Aminophenols were from Merck for synthesis and the water employed for the preparation of the solutions was obtained from a Millipore-Milli-Q plus system. $\mathrm{D}_{2} \mathrm{O}$ was from Aldrich chemicals, $99.9 \%$ atom $\%$ D. A reversible hydrogen electrode (RHE) was used which is immersed in the same solution.

The polycrystalline platinum electrode was thermally cleaned and subsequently protected from the laboratory atmosphere by a droplet of ultrapure water. Then, it was transferred to the working solution (previously deaerated by bubbling $\mathrm{N}_{2}$ ) where it was immersed at controlled potential. The cyclic voltammograms were recorded at a constant sweep rate of $50 \mathrm{mV} \mathrm{s}^{-1}$, at room temperature.

A Nicolet Magna 850 spectrometer equipped with a liquid nitrogen-cooled MCT detector was employed for the in situ FTIR measurements. The sample compartment was purged throughout the experiment using a 7550 Balston clean air package. The electrode used was a polycrystalline platinum disc $8 \mathrm{~mm}$ in diameter obtained from Goodfellow Metals (purity 99.99\%). The disc was mounted on a glass tube and its surface was polished using alumina powder of several sizes $(1,0.3$ and 0.05 $\mu \mathrm{m})$. A platinum electrode was used as the counterelectrode. The thin-layer spectroelectrochemical cell was made of glass and was provided with a prismatic $\mathrm{CaF}_{2}$ window bevelled at $60^{\circ}$. Spectra were collected at $8 \mathrm{~cm}^{-1}$ resolution and are presented as $\Delta R / R$.

Molecular modeling of reactants and intermediates was performed with Hyperchem 5.0 using the semi-empirical self-consistent field method (AM1).

\section{Results and discussion}

\section{1. p-Aminophenol oxidation}

Fig. 1, dotted line, shows the steady state voltammogram obtained for a polycrystalline platinum elec-

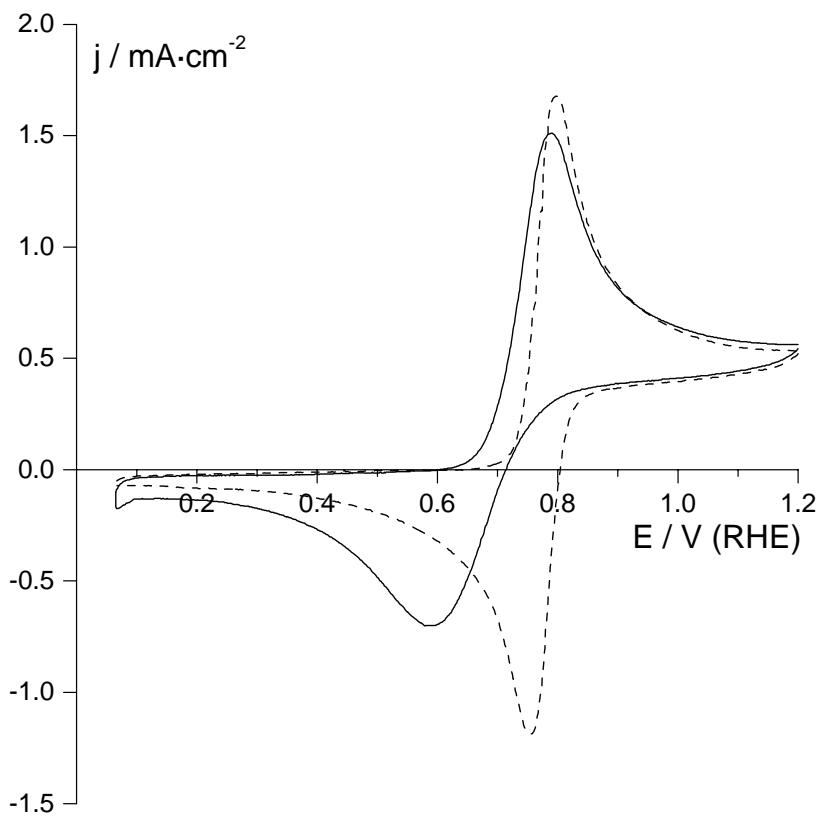

Fig. 1. Steady state voltammogram for a Pt electrode immersed in $1 \mathrm{M}$ $\mathrm{HClO}_{4}+5 \times 10^{-3}$ M $p$-aminophenol solution (dashed line). Steady state voltammogram for a $\mathrm{Pt}$ electrode immersed in $1 \mathrm{M} \mathrm{HClO}_{4}+$ $5 \times 10^{-3} \mathrm{M}$ hydroquinone (solid line). $v=50 \mathrm{mV} \mathrm{s}^{-1}$.

trode in $1 \mathrm{M} \mathrm{HClO}_{4}+5 \times 10^{-3} \mathrm{M} p$-aminophenol (pAP). The electrode was immersed at $0.2 \mathrm{~V}$ and the potential was swept to more positive values. The voltammogram shows, beginning in the first positive cycle, a quasi-reversible peak at approximately $0.8 \mathrm{~V}$ with its corresponding reduction counterpart at $0.75 \mathrm{~V}$ during the reverse scans. Subsequent cycling of the electrode between 0.06 and $1.2 \mathrm{~V}$ does not alter the voltammogram profile. Therefore, this result suggests a reversible electrochemical reaction without the formation of a polymer film on the electrode surface. The redox couple observed in the voltammogram is very similar to that obtained in the oxidation of hydroquinone under the same conditions. Fig. 1, solid line, shows the steady state voltammogram recorded for a platinum electrode in a $1 \mathrm{M} \mathrm{HClO}_{4}+5 \times 10^{-3} \mathrm{M}$ hydroquinone solution. The oxidation of hydroquinone to $p$-benzoquinone occurs to a potential $10 \mathrm{mV}$ less positive than that for pAP. The reversible reduction peak appears shifted $150 \mathrm{mV}$ to lower potentials. Thus, despite of these differences, the possibility of obtaining hydroquinone/benzoquinone as the hydrolysis product of pAP is not discarded as has been proposed previously [31].

Fig. 2 shows the in situ FTIR spectra obtained for a polycrystalline platinum electrode in $1 \mathrm{M}$ $\mathrm{HClO}_{4}+5 \times 10^{-3} \mathrm{M}$ pAP solution in water and deuterated water. After the flame treatment of the platinum electrode, it was immersed at $0.4 \mathrm{~V}$ (reference potential) into the spectroelectrochemical cell and was pressed against the $\mathrm{CaF}_{2}$ window. The potential was stepped up 


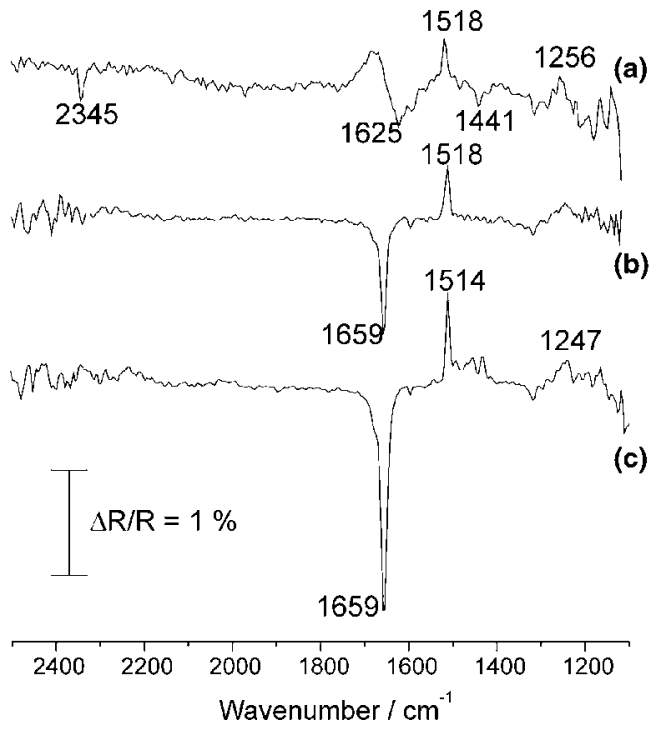

Fig. 2. FTIR spectra for a Pt electrode in a $1 \mathrm{M} \mathrm{HClO}_{4}+5 \times 10^{-3} \mathrm{M}$ p-aminophenol solution; (a) water and (b) deuterated water. (c) FTIR spectrum for a Pt electrode in a $1 \mathrm{M} \mathrm{HClO}_{4}+5 \times 10^{-3} \mathrm{M}$ hydroquinone in deuterated water. p-polarized light. 100 interferograms. Reference potential: 0.4 and sample potential: $1 \mathrm{~V}$.

to $1 \mathrm{~V}$ and the sample spectrum was collected. In this way the spectrum obtained contains information about the redox reaction undergone by the pAP. Fig. 2(a) shows the spectrum obtained in water as the solvent in which two positive bands at 1518 and $1256 \mathrm{~cm}^{-1}$ are clearly observed in the spectrum. The band at $1518 \mathrm{~cm}^{-1}$ can be assigned to the $\mathrm{C}=\mathrm{C}$ aromatic stretching and the band at $1256 \mathrm{~cm}^{-1}$ to the $\mathrm{O}-\mathrm{H}$ deformation vibration and $\mathrm{C}-\mathrm{O}$ stretching vibration of phenols [32]. The positive character of these bands indicates that these groups are disappearing in the sample potential. A negative band at $2345 \mathrm{~cm}^{-1}$ also appears, corresponding to the formation of $\mathrm{CO}_{2}$ in solution. A negative band at $1625 \mathrm{~cm}^{-1}$ is also observed, but this spectral region near $1640 \mathrm{~cm}^{-1}$ suffers interference from the absorption band of water. A negative band at $1441 \mathrm{~cm}^{-1}$ is also clearly observed in the spectrum but its assignation is not clear. A spectrum under the same conditions was obtained but in deuterated water (Fig. 2(b)). In this spectrum, a very clear negative band at $1659 \mathrm{~cm}^{-1}$ is observed. This band is associated with $\mathrm{C}=\mathrm{O}$ stretching of quinone but also with the $\mathrm{C}=\mathrm{N}$ stretching vibration of imines [32]. The negative character of this band indicates that these groups are produced as a consequence of the oxidation of pAP (sample potential). Thus, we can suggest that the oxidation of pAP produces quinonimine as is presented in Scheme 1.

It has been proposed that the electrochemical oxidation of pAP in acid media is coupled with a slow chemical hydrolytic reaction, rendering benzoquinone as the final product [31] (Scheme 1). To check whether the observed bands are due to the hydrolysis product, the
FTIR spectra of hydroquinone was recorded in deuterated water (Fig. 2(c)). The spectrum was obtained for the same sample and reference potentials as in the case of pAP and it is similar to that obtained in the case of pAP (Fig. 2(b)). The spectrum of hydroquinone (Fig. 2(c)) shows a positive band at $1514 \mathrm{~cm}^{-1}$ corresponding to the disappearance of the aromatic ring and a negative clear band at $1659 \mathrm{~cm}^{-1}$ that indicates the formation of the carbonyl group of $p$-benzoquinone. Now the band at $1441 \mathrm{~cm}^{-1}$ that appeared in the spectrum of Fig. 2(a) could be associated with the formation of ammonium ion in the solution as is presented in Scheme 1. Thus, we can conclude that the final oxidation products of pAP are $p$-benzoquinone, $\mathrm{CO}_{2}$ and ammonium ion, the former is responsible for the redox couple observed in the cyclic voltammogram. No polymeric material was detected on the electrode.

\section{2. m-Aminophenol oxidation}

Fig. 3 shows the voltammograms for a polycrystalline platinum electrode in $1 \mathrm{M} \mathrm{HClO}_{4}+5 \times 10^{-3} \mathrm{M} \mathrm{m}$ aminophenol (mAP) solution. In contrast to $p$-aminophenol, the cyclic voltammograms of mAP reveal an oxidation current at $1.1 \mathrm{~V}$ during the first positive cycle without its reduction peak in the reverse scan, indicating a fast follow up chemical reaction. The second cycle shows a lower oxidation current, suggesting the formation of a blocking film on the electrode surface. Indeed, after the fiftieth cycle the electrode is removed from the mAP solution and washed with ultrapure water and immersed again in a $1 \mathrm{M} \mathrm{HClO}_{4}$ solution free of mAP. Fig. 4 shows the voltammogram obtained with the covered platinum electrode under these conditions, in which the characteristic voltammetric profile for a clean platinum electrode is not observed (Fig. 4, dashed line). The adsorption-desorption processes that occur between 0.06 and $0.5 \mathrm{~V}$ are blocked and the current density associated with the surface oxidation is smaller than that obtained for a clean platinum electrode. This behavior confirms the formation of a blocking polymeric film.

In order to analyse the species produced during the oxidation of mAP, in situ FTIR spectroscopy was performed. Fig. 5 shows the spectra obtained for a polycrystalline platinum electrode in a $1 \mathrm{M} \mathrm{HClO}_{4}+5 \times 10^{-3}$ $\mathrm{M}$ mAP solution. After the flame treatment, the electrode was introduced into the working solution at $0.2 \mathrm{~V}$ and the reference spectrum (100 interferograms) was collected. The potential was then stepped to higher values, taking 100 interferograms at each step. Only two spectra are presented in Fig. 5 obtained under these conditions. When the potential is $1 \mathrm{~V}$ (Fig. 5(a)) no clear bands appear in the spectrum, however, at $1.2 \mathrm{~V}$ (Fig. 5(b)) two positive bands at 1498 and $1295 \mathrm{~cm}^{-1}$ are clearly observed. The band at $1498 \mathrm{~cm}^{-1}$ can be assigned to the $\mathrm{C}=\mathrm{C}$ stretching vibration of the aromatic ring, 


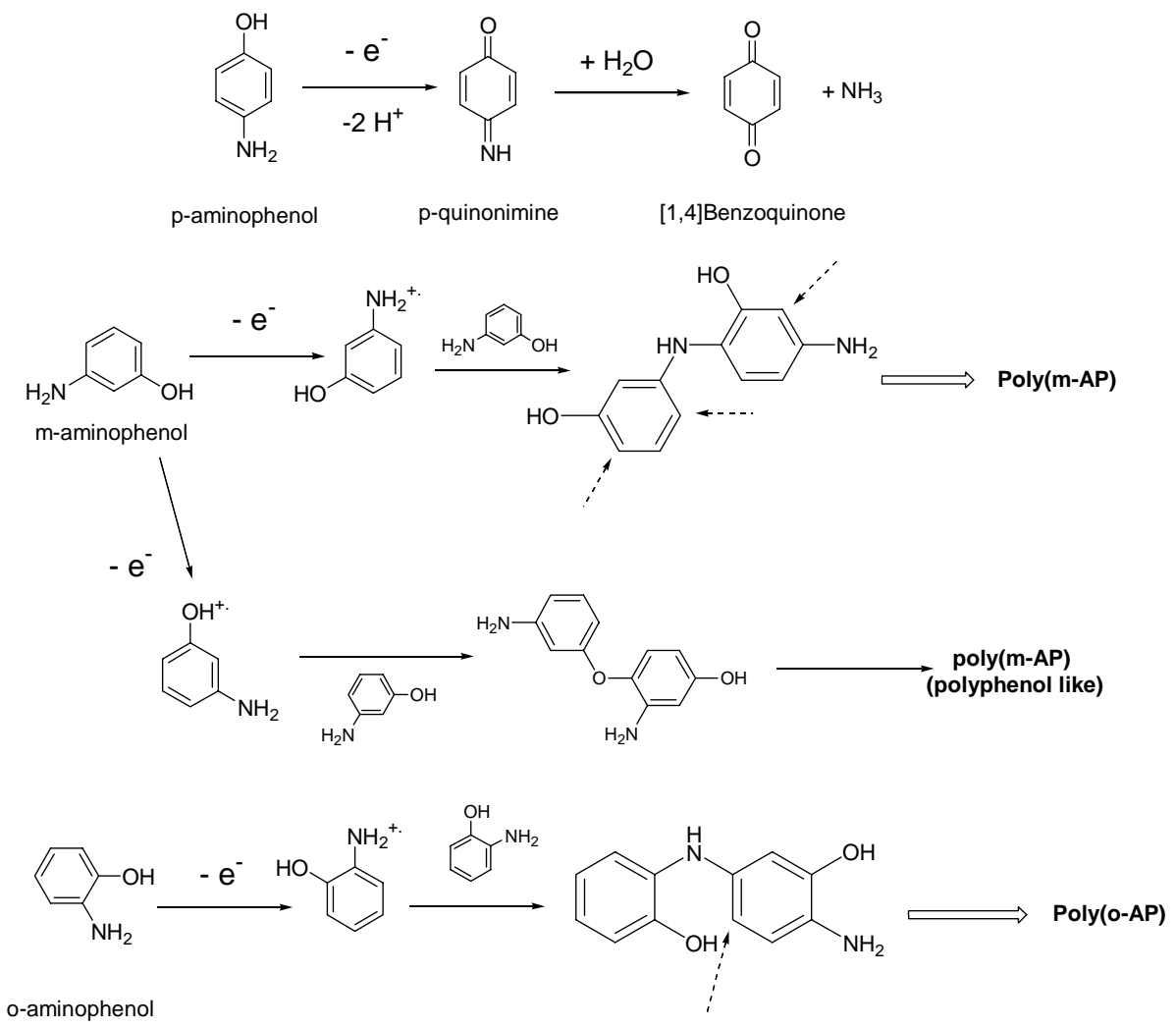

Scheme 1.

and the band at $1295 \mathrm{~cm}^{-1}$ to the $\mathrm{C}-\mathrm{O}$ stretching vibration of an alcohol group [32]. The positive character of these bands indicates that these groups are disap-

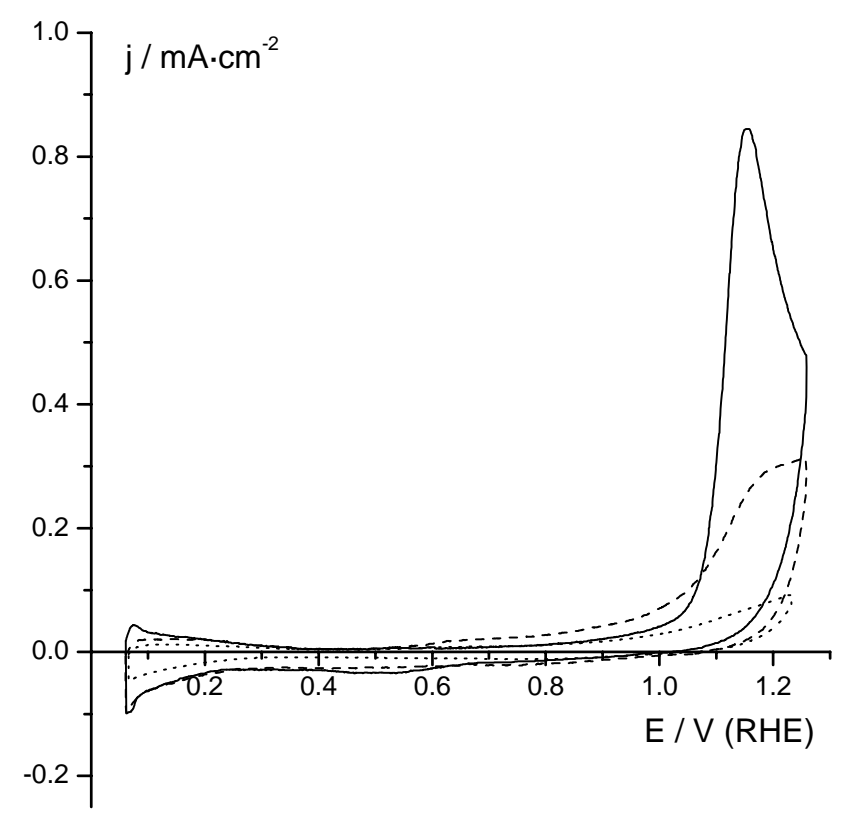

Fig. 3. Cyclic voltammograms recorded for a Pt electrode in $1 \mathrm{M}$ $\mathrm{HClO}_{4}+5 \times 10^{-3} \mathrm{M} m$-aminophenol solution. ( - ), first cycle; $(---)$, second cycle and $(\cdots \cdots)$, fiftieth cycle. $v=50 \mathrm{mV} \mathrm{s}^{-1}$. pearing at the sample potential (higher potential values). A strong band at $2345 \mathrm{~cm}^{-1}$ is also observed corresponding to the formation of $\mathrm{CO}_{2}$ in solution produced

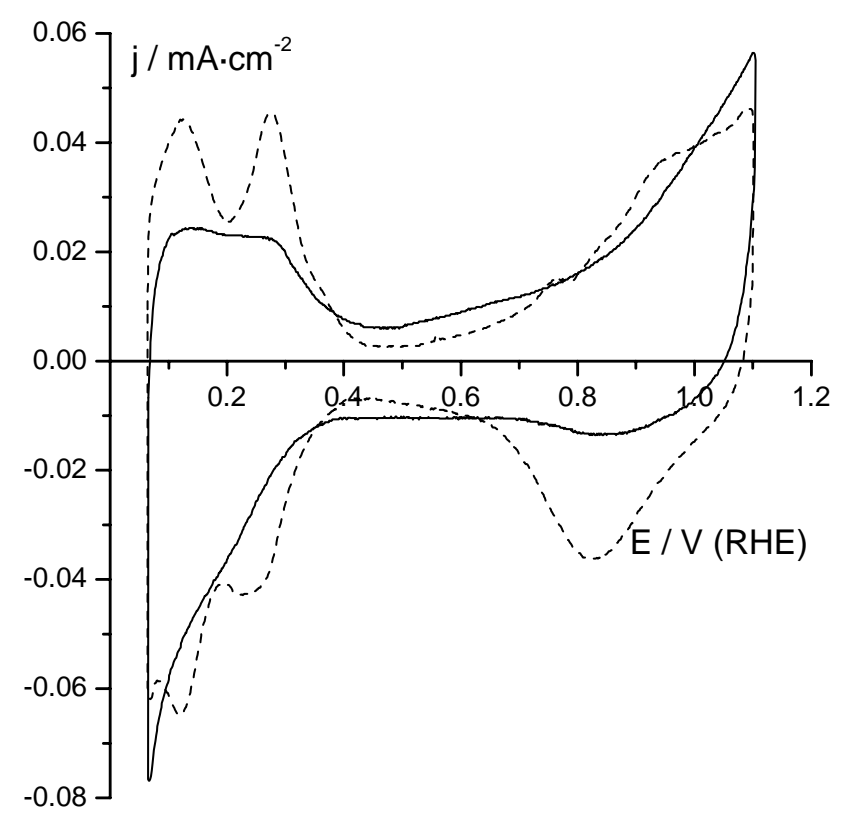

Fig. 4. (- Steady state voltammogram for a Pt electrode covered by the polymeric film created after 50 cycles as in Fig. $4.1 \mathrm{M} \mathrm{HClO}_{4}$ solution. (- - - - ) Steady state voltammogram for a clean Pt electrode in $1 \mathrm{M} \mathrm{HClO}_{4}$ solution. $v=50 \mathrm{mV} \mathrm{s}^{-1}$. 


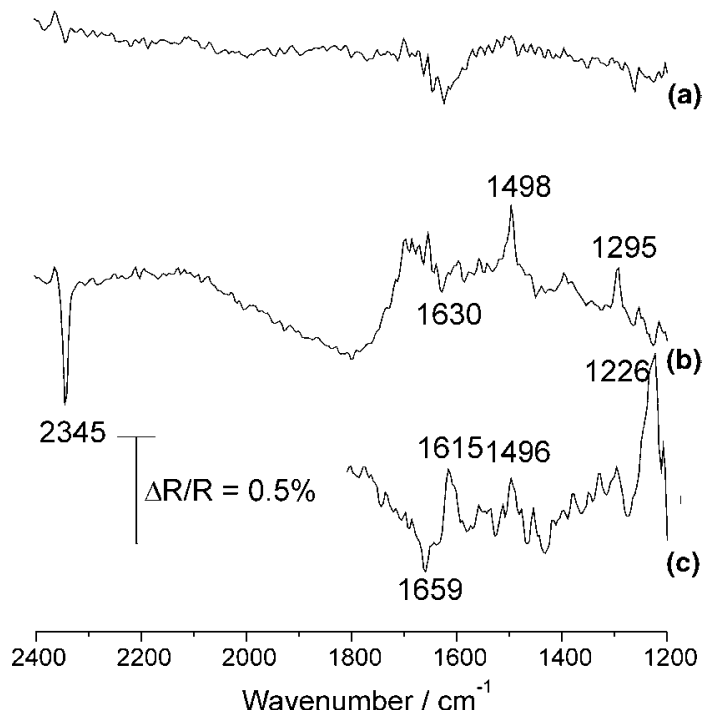

Fig. 5. FTIR spectra for a Pt electrode in a $1 \mathrm{M} \mathrm{HClO}_{4}+5 \times 10^{-3} \mathrm{M}$ $m$-aminophenol solution. (a) Sample potential: $1 \mathrm{~V}$, (b) sample potential: $1.2 \mathrm{~V}$, (c) spectrum obtained at $1.2 \mathrm{~V}$ in deuterated water. $\mathrm{p}$ polarized light. 100 interferograms. Reference potential: $0.2 \mathrm{~V}$.

in the oxidation of mAP. A very small band at 1630 $\mathrm{cm}^{-1}$ is also observed, however, this spectral region suffers interference from the absorption of water. Fig. 5(c) shows the spectrum at $1.2 \mathrm{~V}$ obtained under the same conditions as the spectrum of Fig. 5(b) but in deuterated water. This spectrum shows the same bands that appears in Fig. 6(b), that is a positive bands at 1496 $\mathrm{cm}^{-1}$ corresponding to the aromatic ring and at 1226 $\mathrm{cm}^{-1}$ corresponding to the alcohol group. Additional bands are observed in the spectrum between 1700 and $1600 \mathrm{~cm}^{-1}$. A negative band at $1659 \mathrm{~cm}^{-1}$ can be associated to the $\mathrm{C}=\mathrm{O}$ stretching vibration of quinones that are produced in the oxidation of mAP. A positive band at $1615 \mathrm{~cm}^{-1}$ is also observed that could be assigned to the $\mathrm{N}-\mathrm{H}$ deformation vibration of aromatic amines, the character of this band indicates that this species is disappearing at the sample potential. Thus, during the oxidation of mAP, quinone and $\mathrm{CO}_{2}$ were detected by FTIR as the main soluble products.

\section{3. o-Aminophenol oxidation}

Fig. 6 shows the voltammograms for a polycrystalline platinum electrode in $1 \mathrm{M} \mathrm{HClO}_{4}+5 \times 10^{-3} \mathrm{M}$ oAP solution. The cyclic voltammogram of oAP in acid medium shows during the first positive sweep to higher potentials an oxidation peak at $0.86 \mathrm{~V}$ without a cathodic counterpart during the reverse direction. However, during the backward scan, a new peak at 0.53 appears. This peak has its anodic counterpart in the second scan in the positive direction at $0.55 \mathrm{~V}$ (Fig. 6, dashed line). This redox system has been attributed [28] to the head to tail dimer, 4-amino, 2',3-dihydroxydi-

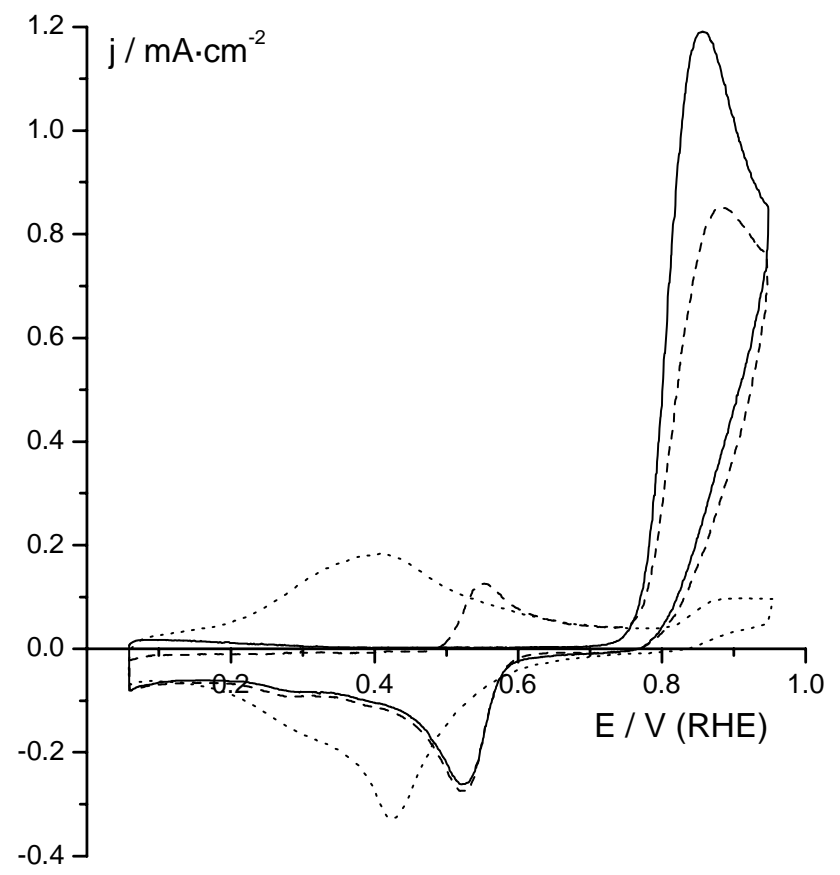

Fig. 6. Cyclic voltammograms obtained for a Pt electrode in FTIR spectra for a Pt electrode in a $1 \mathrm{M} \mathrm{HClO}_{4}+5 \times 10^{-3} \mathrm{M} o$-aminophenol solution. ( - ), first cycle; $(---)$, second cycle and $(\cdots \cdots)$, onehundredth cycle. $v=50 \mathrm{mV} \mathrm{s}^{-1}$.

phenylamine. By subsequent cycling, the monomer oxidation peak at $0.86 \mathrm{~V}$ decreases somewhat, indicating a partial blockage of the surface, and a new redox systems develops between 0.2 and $0.5 \mathrm{~V}$ which has been assigned to a cyclic dimer (3-aminophenoxazone (3APZ)) and/or the electroactive polymer (poly(oAP)) (Fig. 6, dotted line). If under these conditions the covered platinum electrode is removed from the electrochemical cell, washed with water and introduced in a $1 \mathrm{M} \mathrm{HClO}_{4}$ solution free of oAP, the voltammogram of Fig. 7 is obtained. This behavior has been attributed to that corresponding to the electroactive polymer (poly(oAP)) obtained in the oxidation of oAP $[10,13,14]$.

In situ FTIR spectroscopy has been employed to study the oxidation of oAP in acid medium. Fig. 8 shows the spectra obtained for a polycrystalline platinum electrode in $1 \mathrm{M} \mathrm{HClO}_{4}+5 \times 10^{-3} \mathrm{M}$ oAP solution. The electrode was immersed at $0.1 \mathrm{~V}$ into the spectroelectrochemical cell and was pressed against the $\mathrm{CaF}_{2}$ window. The potential was stepped up to $0.4 \mathrm{~V}$ and the reference spectrum was collected (100 interferograms). The potential was then polarized to higher values to oxidise the oAP and the sample spectra were acquired at 0.8 and $1 \mathrm{~V}$. In the spectrum at $0.8 \mathrm{~V}$ (Fig. 8(a)) two positive bands at 1510 and $1471 \mathrm{~cm}^{-1}$ appear. These two positive bands can be assigned to the aromatic $\mathrm{C}=\mathrm{C}$ stretching vibration and $\operatorname{ring} \mathrm{C}=\mathrm{C}$ vibration of meta-disubstituted benzenes [31]. The positive character of these bands reflects that there is consump- 


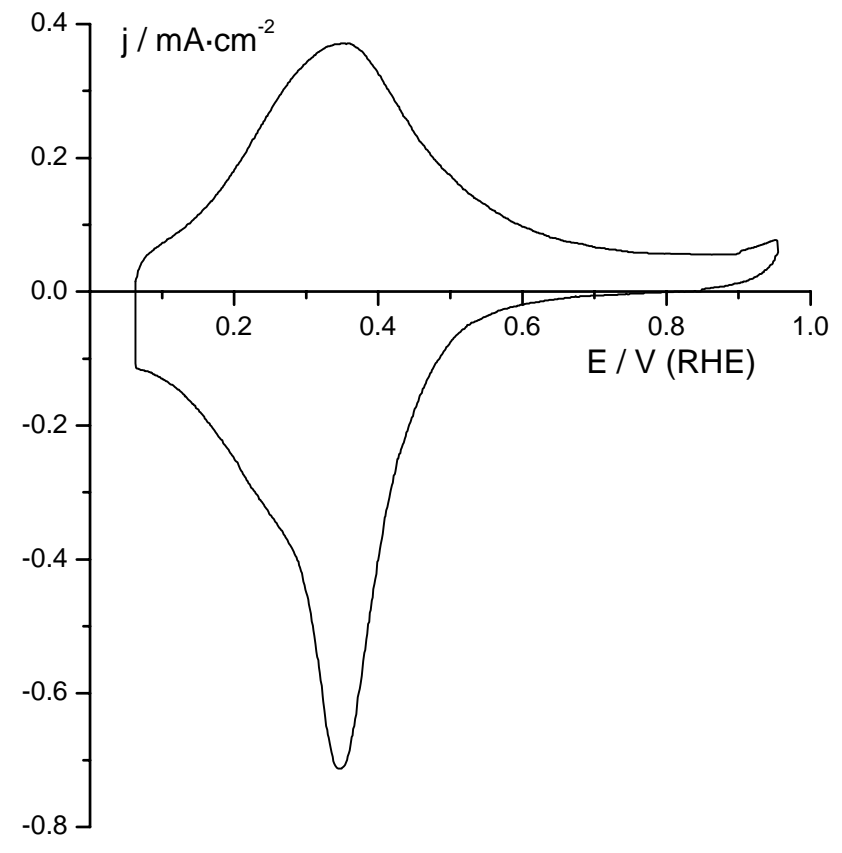

Fig. 7. Cyclic voltammogram obtained for a Pt electrode covered by the conducting polymer created by 300 cycles as in Fig. 4 in $1 \mathrm{M}$ $\mathrm{HClO}_{4}$ solution. $v=100 \mathrm{mV} \mathrm{s}^{-1}$.

tion of the species related to these features at the sample potential. At $1 \mathrm{~V}$ (Fig. 8(b)) these bands are also observed together with a strong band at $2342 \mathrm{~cm}^{-1}$ corresponding to the formation of $\mathrm{CO}_{2}$ in the solution. No clear bands appear at lower sample potentials. When the same spectrum is collected in deuterated water (Fig. 8(c)), two negative bands at 1683 and $1645 \mathrm{~cm}^{-1}$ appear. These bands are associated with the $\mathrm{C}=\mathrm{O}$ and $\mathrm{C}=\mathrm{N}$ stretching vibrations, respectively [32].

The only electroactive polymer obtained by the oxidation of the isomers of aminophenol is that obtained with oAP (poly(oAP)). While the polymer has been studied using ex situ techniques [12,14,33], in situ techniques could show a better insight into the polymer structure and redox reactions.

In Fig. 7 the electrochemical response of the polymer film has been shown, in the absence of the monomer. A broad anodic peak is observed, with a sharper reduction counterpart. It has been assumed that only one redox process occurs in poAP. The redox response of poly(oAP) is usually due to the oxidation-reduction of phenoxazine units in the polymer $[11,28]$. However, an alternative structure for the polymer has been proposed where the polymer remains linear and the $-\mathrm{OH}$ groups are free and could be oxidized to ortho-quinonimines [25]. There is little spectroscopic support for the structure of the poly(oAP). Moreover, the agreement of redox potential and spectroscopic data between $3 \mathrm{APZ}$ and the polymer suggests that the main chain contains phenoxazine units. It is likely that some open units remain in the polymer, as it has been suggested before [14].

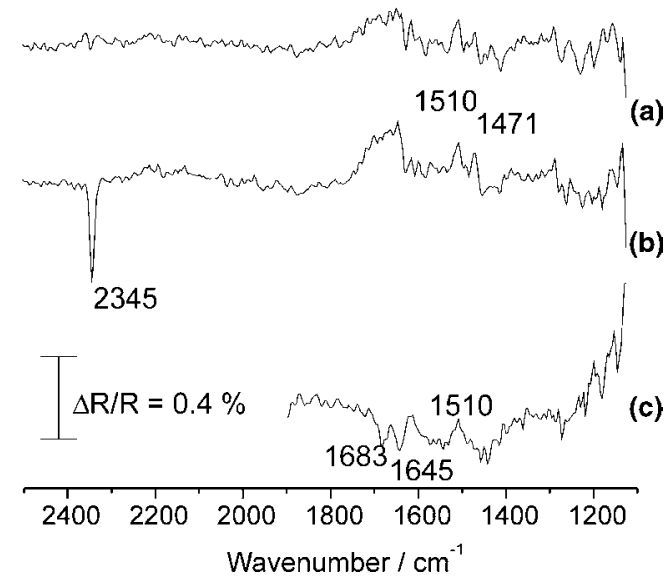

Fig. 8. FTIR spectra for a Pt electrode in a $1 \mathrm{M} \mathrm{HClO}_{4}+5 \times 10^{-3} \mathrm{M}$ $o$-aminophenol solution. (a) Sample potential: $0.8 \mathrm{~V}$, (b) sample potential: $1 \mathrm{~V}$, (c) spectrum obtained at $0.9 \mathrm{~V}$ in deuterated water. $\mathrm{p}$ polarized light. 100 interferograms. Reference potential: 0.4 .

To try to clarify the structure of the polymer formed during the redox processes of poly(oAP), in situ FTIR spectroscopy was employed. Figs. 9(a) and (b) show the spectra of a poly(oAP) in $1 \mathrm{M} \mathrm{HClO}_{4}$ solution, in the absence of oAP, in water and deuterated water, respectively. The reference spectrum was acquired at $0.1 \mathrm{~V}$ (100 interferograms), so it contains the vibrational information corresponding to the reduced form of the film. The electrode is then polarized to $0.7 \mathrm{~V}$ and the sample spectrum was collected. Similar bands are observed in both spectra. Fig. 9(a) displays two clear po-

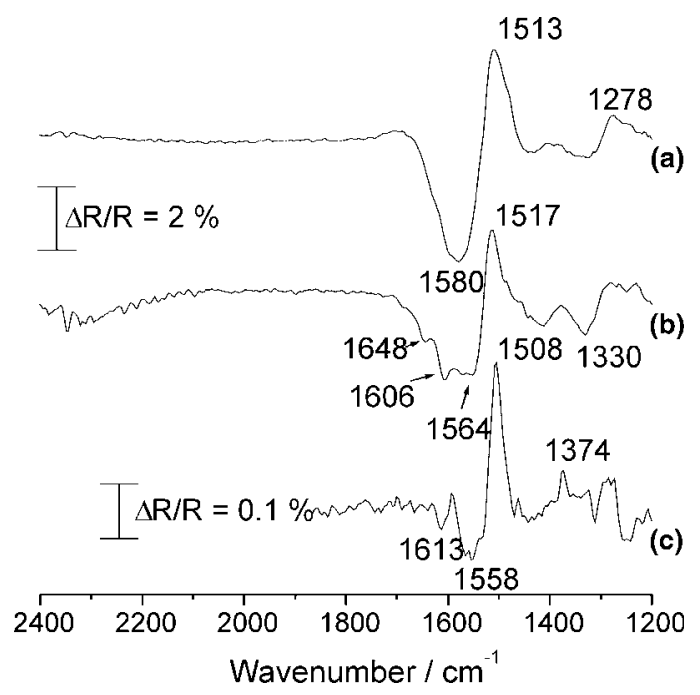

Fig. 9. FTIR spectra for a Pt electrode covered with the conducting polymer of poly(oAP) in a $1 \mathrm{M} \mathrm{HClO}_{4}$ solution in (a) water and (b) deuterated water. Sample potential: $0.7 \mathrm{~V}$ and reference potential: 0.1 V. p-polarized light. 100 interferograms. (c) FTIR spectrum obtained for a Pt electrode in $1 \mathrm{M} \mathrm{HClO}_{4}+5 \times 10^{-4} \mathrm{M}$ phenoxazine solution in deuterated water. Sample potential: $0.7 \mathrm{~V}$ and reference potential: 0.4 V. p-polarized light. 1000 interferograms. 
sitive bands at 1513 and $1278 \mathrm{~cm}^{-1}$, and a broad negative band at $1580 \mathrm{~cm}^{-1}$. The band at $1513 \mathrm{~cm}^{-1}$ is also present in the spectra in $\mathrm{D}_{2} \mathrm{O}$ (Fig. 9(b)) but in this case it appears at $1517 \mathrm{~cm}^{-1}$ and could be assigned to the $\mathrm{C}=\mathrm{C}$ stretching of the aromatic ring, which disappears upon polymer oxidation (Scheme 2). The broad negative band at $1580 \mathrm{~cm}^{-1}$ is also present in deuterated water but in this case, the band has contributions from several bands at 1564, 1606 and $1648 \mathrm{~cm}^{-1}$ and could be assigned to a quinoid ring or $\mathrm{C}=\mathrm{N}$ stretching vibration in the phenoxazine units produced upon complete polymer oxidation (Scheme 2). The $1648 \mathrm{~cm}^{-1}$ band could be assigned to $\mathrm{C}=\mathrm{N}$ stretching, where conjugation with the phenyl group shifts its frequency to higher values [34] and it is more clearly observed in deuterated water due to the reduced interference of water absorptions. Another negative band can be seen at $1330 \mathrm{~cm}^{-1}$ in both spectra which is also clearly seen at low potentials (spectra not shown) that could also be assigned to $\mathrm{C}=\mathrm{N}$ stretching of quinoid rings containing $\mathrm{C}=\mathrm{N}$ and $\mathrm{C}-\mathrm{N}$ groups, as has been done in polyaniline [35].

In order to check this assignation, the spectra for phenoxazine in the same range of potentials have been obtained. Fig. 9(c) shows the spectrum obtained for a polycrystalline platinum electrode immersed in a $1 \mathrm{M}$ $\mathrm{HClO}_{4}+5 \times 10^{-4} \mathrm{M}$ phenoxazine solution in deuterated water. After the flame treatment of the electrode it was introduced at $0.2 \mathrm{~V}$ in the spectroelectrochemical cell and a series of reference and sample spectra were collected alternately at 0.2 and $0.7 \mathrm{~V}$ and then co-added. The spectrum obtained shows a sharp and negative band at $1508 \mathrm{~cm}^{-1}$ corresponding to the disappearance of the aromatic ring at the sample potential. A positive band at $1374 \mathrm{~cm}^{-1}$ is also observed that can be assigned to the $\mathrm{C}-\mathrm{N}$ stretching vibration of a secondary aromatic amine [32] that also disappears at $0.7 \mathrm{~V}$. Two negative bands appear at $1558 \mathrm{~cm}^{-1}$ that can be associated to the $\mathrm{C}=\mathrm{N}$ stretching vibration of the imine group that is produced at higher potentials in the oxidation of phenoxazine. Thus, it can be concluded that the most probable structure of the polymer formed in the oxidation of $o$ aminophenol contains the phenoxazine unit as the main constituent of its structure.

The data discussed above allows us to propose reaction pathways for the electrochemical oxidation of aminophenols.

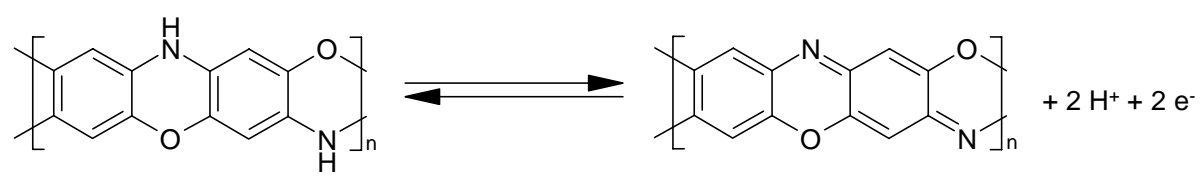

Scheme 2 .

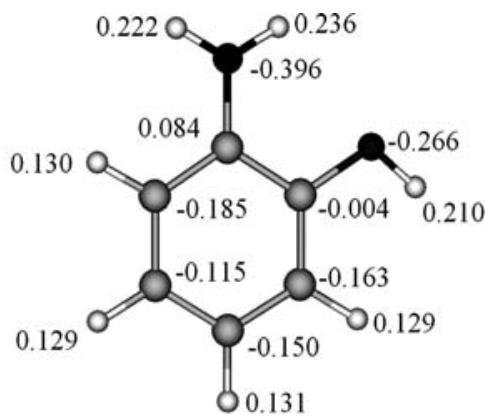

o-aminophenol

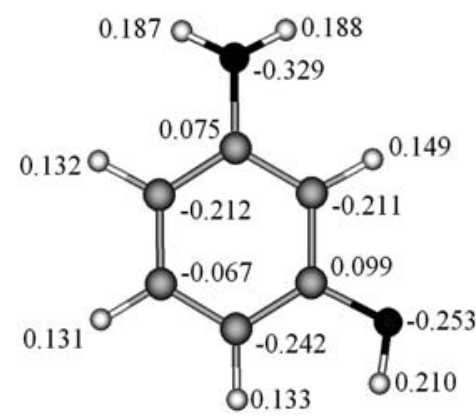

m-aminophenol

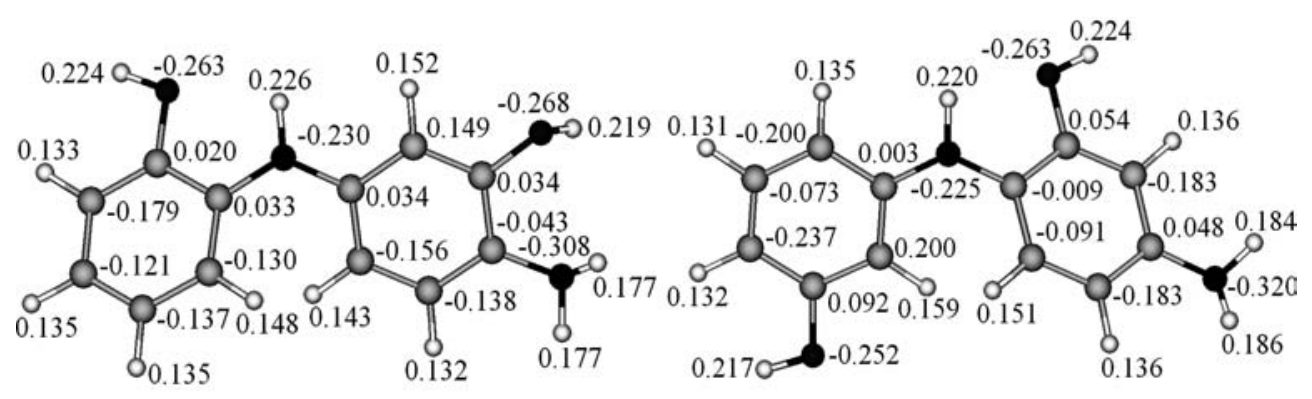

o-aminophenol dimer (N-linked)

m-aminophenol dimer (N-linked)

Fig. 10. Electronic density calculations for oAP and mAP obtained using the semi-empirical self-consistent field method (AM1), together with the head-to-tail (N-linked) dimers. 


\subsection{Comparative reaction mechanism}

The comparative mechanism of aminophenols oxidation and/or polymerization is described in Scheme 1.

The reaction mechanism depends on the position of the amino group in the aminophenol. The $p$-aminophenol cation radical, produced by electrochemical oxidation, could not couple with the free monomer, through head to tail electrophilic substitution, because the para position is blocked. Therefore, the preferred pathway is the formation of $p$-quinonimine which is stabilized by extended conjugation. On the contrary, both $o$-aminophenol and $m$-aminophenol (Fig. 10) have a high electronic density in the para position with respect to the $-\mathrm{NH}_{2}$ group. Therefore, dimers could be formed through attack of the cation radical at that position. The mechanistic difference, towards electrophilic substitution, between $o$-aminophenol and $m$-aminophenol is apparent in the electronic density distribution of the dimers (Fig. 10). The dimer of $o$-aminophenol has the higher electronic density in the para position with respect to the $-\mathrm{OH}$ group, allowing closing of the phenoxazine ring. The resulting polymer will have a ladder type structure built in by phenozaxine units. On the other hand, the dimer of $m$-aminophenol has several positions with similar electronic densities (Fig. 10), favoring multiple addition of cation radicals to the dimer. Therefore, the resulting polymer will have a crosslinked structure. Such a structure is more likely to have low conductivity. An alternative is the dimerization of $m$ aminophenol in a head to tail fashion (linked by the $\mathrm{O}$ ) (Scheme 1). Successive additions of radical cation to the mAP will produce a linear poly(ether) much like polyphenol. Such a polymer is likely to be insulating. It is noteworthy that a linear polyamine with pendant $-\mathrm{OH}$ groups will be electroactive and this seems not to be produced.

\section{Conclusions}

The electrochemical oxidation of para-, meta- and ortho-aminophenols has been investigated by means of cyclic voltammetry and in situ FTIR spectroscopy on a platinum electrode. The three isomers of aminophenol show different electrochemical behavior on platinum electrodes. Thus, the $p$-aminophenol shows a cyclic voltammogram with a quasi-reversible redox couple without formation of polymeric product. The spectroscopic results indicate that $p$-aminophenol suffers hydrolysis giving the formation of hydroquinone/ $p$ benzoquinone in solution. Additionally, ammonium ion and $\mathrm{CO}_{2}$ are detected by FTIR spectroscopy.

The electrochemical oxidation of $m$-aminophenol produces a polymeric product on the platinum surface that inhibits the subsequent oxidation of $m$-aminophe- nol. The polymeric product could have a crosslinked or a linear structure analogous to polyphenol. The main soluble oxidation products detected by in situ infrared spectroscopy were $\mathrm{CO}_{2}$ and quinone.

The electrochemical oxidation of $o$-aminophenol produces electroactive dimers which polymerize to form an electroactive material on the platinum surface. Cyclic voltammetry and in situ FTIR spectroscopy were combined to study the redox processes of the conducting polymer obtained in the $o$-aminophenol oxidation. Comparison with the model compound indicates that phenoxazine units are the main units of the poly $(o-$ aminophenol) backbone.

\section{Acknowledgements}

Financial support by the Generalitat Valenciana (GV01-313) and Ministerio de Ciencia y Tecnología (MAT2001-1007) projects, as well as CONICET, SECYT-UNRC, Agencia Córdoba Ciencia and FONCYT (Argentina) are gratefully acknowledged. C. Barbero is a permanent research fellow of CONICET. H.J.S. thanks FONCYT for a graduate fellowship. Financing of the collaboration between Universidad de Alicante and UNRC by Fundación Antorchas is gratefully acknowledged.

\section{References}

[1] H. Yang, A.J. Bard, J. Electroanal. Chem. 339 (1992) 423.

[2] N. Yamada, K. Teshima, N. Kobayashi, R. Hirohashi, J. Electroanal. Chem. 394 (1995) 71.

[3] J. Chiang, A.G. MacDiarmid, Synth. Met. 13 (1986) 193.

[4] M. Gattrell, D.W. Kirk, J. Electrochem. Soc. 139 (1992) 2736.

[5] R. Lapuente, F. Cases, P. Garcés, E. Morallón, J.L. Vázquez, J. Electroanal. Chem. 451 (1998) 163.

[6] R. Andreozzi, M.S. Lo Casale, R. Martota, G. Pinto, A. Pollio, Water Res. 34 (2000) 4419.

[7] W. Sun, K. Jiao, S. Zhang, C. Zhang, Z. Zhang, Anal. Chim. Acta 434 (1) (2001) 43.

[8] Sh. Taj, M.F. Ahmed, S. Sankarapapavinasam, J. Electroanal. Chem. 338 (1992) 347

[9] O.I. Konopelnik, O.I. Aksimentyeva, M.Y. Grytsiv, Mater. Sci. 20 (2002) 49.

[10] C. Barbero, J. Zerbino, L. Sereno, D. Posadas, Electrochim. Acta 32 (1987) 341.

[11] T. Ohsaka, S. Kunimura, N. Oyama, Electrochim. Acta 33 (1988) 639.

[12] A. Guenbour, A. Kacemi, A. Benbachir, L. Aries, Prog. Org. Coat. 38 (2000) 121.

[13] C. Barbero, J.J. Silber, L. Sereno, J. Electroanal. Chem. 263 (1989) 333.

[14] S. Kunimura, T. Oshaka, N. Oyama, Macromolecules 21 (1988) 894.

[15] Y. Yang, Z. Lin, Synth. Met. 78 (1996) 111.

[16] C. Barbero, R.I. Tucceri, D. Posadas, J.J. Silber, L. Sereno, Electrochim. Acta 40 (1995) 1037.

[17] F.J. Rodríguez Nieto, D. Posadas, R.I. Tucceri, J. Electroanal. Chem. 434 (1997) 83. 
[18] R.I. Tucceri, C. Barbero, J.J. Silber, L. Sereno, D. Posadas, Electrochim. Acta 42 (1997) 919.

[19] A.Q. Zhang, C.Q. Cui, Y.Z. Chen, J.Y. Lee, J. Electroanal. Chem. 373 (1994) 115.

[20] T. Komura, Y. Ito, T. Yamaguti, K. Takahasi, Electrochim. Acta 43 (1998) 723.

[21] J.M. Ortega, Thin Solid Film 371 (2000) 28.

[22] R.I. Tucceri, J. Electroanal. Chem. 505 (2001) 72.

[23] M.A. Valdes Garcia, P. Tuñon Blanco, A. Ivaska, Electrochim. Acta 43 (1998) 3533.

[24] M.J. Lobo, A.J. Miranda, J.M. López-Fonseca, P. Tuñón, Anal. Chim. Acta 325 (1996) 33.

[25] J. Yano, H. Kawakami, S. Yamasaki, Synth. Met. 102 (1999) 1335.

[26] J.M. Ortega, Thin Solid Films 360 (2000) 159.

[27] N. Hernández, J.M. Ortega, M. Choy, R. Ortiz, J. Electroanal. Chem. 515 (2000) 123.
[28] C. Barbero, J.J. Silber, L. Sereno, J. Electroanal. Chem. 263 (1989) 333.

[29] J. Kaizer, R. Csonka, G. Speier, J. Mol. Catal. A 180 (2002) 91.

[30] D. Goncalves, R.C. Faria, M. Yonashiro, L.O.S. Bulhoes, J. Electroanal. Chem. 487 (2000) 90.

[31] Z. Wang, X. Li, Y. Wu, Y. Tang, Sh. Ma, J. Electroanal. Chem. 464 (1999) 181.

[32] G. Socrates, Infrared and Raman Characteristic Group Frequencies, third ed., Wiley, New York, 2001.

[33] K. Jackowska, J. Bukowska, A. Kudelski, J. Electroanal. Chem. 350 (1993) 177.

[34] D. Lin-Vien, N.B. Colthup, W.G. Fateley, J.G. Grasselli, Handbook of Infrared and Raman Characteristic Frequencies of Organic Molecules, Academic Press, San Diego, 1991.

[35] A. Zimmerman, U. Künzelmann, L. Dünsch, Synth. Met. 93 (1998) 17. 